\title{
What Is Innovation? A Study of the Definitions, Academic Models and Applicability of Innovation to an Example of Social Housing in England
}

\author{
S. P. Taylor \\ University of Cumbria, Carlisle, England \\ Email: simon_taylor@rocketmail.com
}

How to cite this paper: Taylor, S.P. (2017) What Is Innovation? A Study of the Definitions, Academic Models and Applicability of Innovation to an Example of Social Housing in England. Open Journal of Social Sciences, 5, 128-146.

https://doi.org/10.4236/jss.2017.511010

Received: November 2, 2017

Accepted: November 25, 2017

Published: November 28, 2017

Copyright $\odot 2017$ by author and Scientific Research Publishing Inc. This work is licensed under the Creative Commons Attribution International License (CC BY 4.0).

http://creativecommons.org/licenses/by/4.0/ (c) (i) Open Access

\begin{abstract}
Throughout history innovation has been conceived, defined, interpreted and understood in different ways but what is it? This study looks at innovation starting with a brief history of innovation. It then looks at a sample of the multiple definitions that there are of innovation throughout the literature and from these develops a composite definition. From this composite definition, key components such as the creative process and academic models of creativity are looked at. The research then looks at the applicability of innovation through highlighting two studies carried out in England of innovation being applied within a social housing organisation. Through the application by a two dimensional typology of social innovation they had identified innovation being applied to new services and improvements to existing services. The research concludes that innovation can be identified with the creation of a new product or service or an improvement of an existing product or service.
\end{abstract}

\section{Keywords}

Innovation, Models, Creative, Incubation, Strategic

\section{Introduction}

Society has developed with the implementation of ideas that have come together to create new solutions to problems or improvements to existing systems, processes, products or attempted solutions. Having ideas, implementing them, developing new ways of doing things and improving existing ways of doing things have been part of mankind's history [1]. Ideas and concepts have influenced 
change as well as being influenced by it, reflecting through language the social understanding of the world [2]. The coming together of ideas and the process for developing solutions to problems has been called innovation, but what is it and how does it happen? To answer this question, we first need to understand the history of innovation. We also need to be able to define what it is and some of the definitions within the existing literature need to be examined to understand how it is understood by different sections of the academic, political and professional communities. Creativity and the development of ideas are key components within the innovation process and this research looks at the creative process. There is a significant academic literature on the creative proofs with different models and theories put forward to show how the process works. Several academic models that have been put forward during the twentieth century are examined. A well as understanding what innovation is it is important to understand how it can be applied to the world that people are living in to deliver benefits that improve people's lives. The research looks at two studies that were carried out in England that looked at innovation within social housing providers. To provide a context within which we can focus on innovation, it is worth looking at the history of innovation briefly.

\section{Innovation: History}

Novation was a medieval legal term relating to "renewing an obligation by changing a contract for a new debtor" [1]. The term was rarely used until the twentieth century and used significantly in the early twenty first century. Godin [1] argues that the meaning of the term innovation in the twentieth century has been a resolution between the two contrasting terms of imitation and invention which have evolved through the centuries from ancient Greek philosophy. The imitation of reality was a central theme in the work of Plato and there has been a continuous debate throughout the centuries about art imitating, copying or being an interpretation of reality [3] [4] [5]. Imitation has been considered as invention at different points through history, during the sixteenth and seventeenth centuries in England patents were given to importers of existing inventions to stimulate economic growth instead of to inventors [6] [7] and during the eighteenth century the imitation of goods produced for consumption was considered as invention for improving the quality, design and appearance of these goods [8] [9] [10]. The expansion of consumerism from the sixteenth century [8] together with the development of economic thought around wealth and material prosperity from the seventeenth century [11] provided a context within which the later industrialization processes can be said to have developed.

The renaissance in fourteenth century Europe had fostered a spirit of discovery in the following centuries to seek the new, across all fields of knowledge including the arts, science, literature, history and economics [1]. Scientific discovery and technological advances were allied to invention [12] which by the nineteenth century had become key parts of the industrialization process linked to 
the economics of profit which in turn impacted significantly on society. The application to economic theory of social and technological advances was pioneered by Marx in the nineteenth century [13] [14]. Marx saw the development in industrial production as increasing capital and activity in the wider economy as well as fostering social change [1]. The evolution of economic theory in the twentieth century aligned the efficiencies of production to technological advances, industrial and economic growth [1]. The twentieth century saw the term innovation used by some writers to explain technological change [15] as well as being the subject of a body of literature assessing the processes behind the term. Early theories looked at the psychological aspects associated with innovation, the development of linear process models and the creative dimension of innovation was recognized [1]. Innovation was seen in the mid twentieth century as an instrument of economic growth [16] and economic survival for organizations" [17] [18] [19] [20] [21]. By the late twentieth century the term innovation had become entangled with advancement, technological change, social change and development across many strands of knowledge, across society and personalized to the individual [1]. In the twenty first century the term innovation signifies a myriad of meanings and concepts influenced by different factors over the centuries and some of these definitions are looked at in the next section.

\section{Innovation: Definition}

There are a significant number of definitions of innovation that are used across different fields in academia, industry, government and service provision. The academic literature available relates to a wide spectrum of disciplines and can cut across discipline areas [22] [23]. For this study, it is important to have a definition of innovation that is suitable for the subject and research being undertaken. To do this, different definitions of innovation in the literature has been examined to establish an understanding of the components that make up the concept of innovation and specifically in relation to social housing.

The wide variety of literature and language used about innovation adds to different interpretations and understandings about basic concepts about the meaning of innovation [22] [24]. As well as looking at the different components that make up innovation the literature also provides several models, theories and frameworks to understand innovation. Approaches have been made to establish a unified understanding of innovation [25] which would have some advantages around clarity and single purpose, but it has also been argued that such an approach would not be helpful [26]. The definition of innovation used in this study has been developed following a review of the literature and examination of the components of innovation. It supports the academic research being undertaken through this study to make a meaningful contribution to knowledge.

To start the examination of literature on innovation a selection of the key parts of several definitions from relevant literature are provided below in (Table 1). A note is placed next to each definition to justify its inclusion in the table. 
Table 1. A sample of different definitions of Innovation in the existing literature.

\begin{tabular}{|c|c|c|}
\hline & Definition & Justification \\
\hline 1 & $\begin{array}{l}\text { Creation of new combinations } \\
\text { of existing resources }\end{array}$ & $\begin{array}{l}\text { Schumpeter recognized the } \\
\text { importance of innovation in the 1930s }\end{array}$ \\
\hline 2 & $\begin{array}{l}\text { Implementation of a new or significantly improved product } \\
\text { (good/service) or process (method/practice/relationship) }\end{array}$ & $\begin{array}{l}\text { International guidelines } \\
\text { for proposed definition }\end{array}$ \\
\hline 3 & $\begin{array}{l}\text { Innovation is the creation and implementation of new processes, } \\
\text { products, services and methods of delivery which result in significant } \\
\text { improvements in outcomes, efficiency, effectiveness or quality }\end{array}$ & A widening of the definition \\
\hline 4 & $\begin{array}{l}\text { The successful exploitation of new ideas or ones that } \\
\text { are adopted from other sectors or organizations' }\end{array}$ & The UK government's definition of innovation \\
\hline 5 & Creation and application of good ideas & Australian National Audit Office (ANAO) definition \\
\hline 6 & $\begin{array}{l}\text { A continuous and dynamic process in which } \\
\text { ideas are transformed into value }\end{array}$ & This definition includes value as a part of innovation \\
\hline 7 & $\begin{array}{l}\text { The successful introduction of new services, products, } \\
\text { processes, business models and ways of working }\end{array}$ & $\begin{array}{l}\text { The Economic and Social Research Council (ESRC) includes } \\
\text { business models and ways of working in the definition }\end{array}$ \\
\hline 8 & $\begin{array}{l}\text { The development (generation) and/or use } \\
\text { (adaption) of new ideas or behaviors }\end{array}$ & This definition includes behaviors as well as ideas \\
\hline 9 & $\begin{array}{l}\text { The introduction of new elements into a service-new knowledge, } \\
\text { new organization, new management/skills }\end{array}$ & This definition focuses on the new within a service \\
\hline 10 & $\begin{array}{l}\text { Innovations are in a significant way new and } \\
\text { disruptive towards the routines and structures prevailing }\end{array}$ & $\begin{array}{l}\text { This definition views innovation as } \\
\text { affecting the external environment }\end{array}$ \\
\hline 11 & $\begin{array}{l}\text { Innovation is the process by which } \\
\text { new ideas turn into practical value in the world }\end{array}$ & $\begin{array}{l}\text { This definition focuses on the } \\
\text { practical application of ideas }\end{array}$ \\
\hline
\end{tabular}

Source: 1 [18], 2 [25], 3 [27], 4 [28], 5 [29], 6 [30], 7 [31], 8 [32], 9 [33], 10 [34], 11 [35].

These definitions contribute to the scope of the literature review, understanding of innovation and development of the definition that is used in this research study.

Table 1 shows different definitions of innovation and identifies some core components that make up innovation. It also shows some convergence of ideas and thinking regarding innovation [36]. These core components are taken and put into a composite definition of innovation as "the creative process whereby new or improved ideas are successfully developed and applied to produce outcomes that are practical and of value" [36]. A key component of the composite definition of innovation is the identification of the creative process which is discussed in the next section.

\section{Innovation: The Creative Process}

The creative process links creativity and innovation with the purpose of producing something of value that can be traded, developed and commercially exploited. Cropley et al. [37] say that they prefer the use of the term "value innovation" to more accurately describe the linked process involving creativity 
and innovation as it is more explicit and reflective of that operative environment. They see the linked process between creativity and innovation as one whereby a duality of approach is employed. Klein and Tremblay discuss creation and innovation within the context of urban, social and cultural development linking them as a linear process whereby "creation precedes innovation: and, innovation depends on the social acceptance of creation and the spread of its effects and results" [38]. Within this context the commercial impetus is less of a driving force behind the processes of creation and innovation. These processes and their connection can be viewed in different way and not just in the linear form [38]. A linear interpretation of the relationship between creativity and innovation excludes a range of other ways through which creative activity and innovation can take place as well as imposing a structured view of how creativity and innovation takes place and interrelates. This includes ideas that come into existence randomly or accidentally as well processes that can be unstructured, random and uncontrolled.

It has been suggested by some writers, that only certain people or groupings within society are creative [39] but it has also been claimed that everyone has the capacity to be creative [40]. If it is accepted that everyone has the capacity to be creative and that the processes involved are context dependent, then the unrestrictive nature of these factors would suggest that creative activity and innovation can take place through an infinite number of ways curtailed only by the restrictive factors that are also individual and context dependent.

Many different models of the creative process have been developed by researchers, academics, practitioners and others, however, not all writers agree that the creative process can be shown through a model. Vinacke [41] said that creativity within the artistic process does not follow a model and Wertheimer [42] saw the process of creative thinking as an integrated one. Within these different models there are some consistent themes including combining the development of ideas together with the use of imagination and analysis. The older models tend to look at the start of the creative process as being uncontrolled and linked to the subconscious processes within a person's brain whereas the newer models tend to lean towards it being a controlled generative process.

\section{Creativity: Academic Models}

A study of creativity undertaken by Plsek [43] has highlighted several models within the literature on creativity that are important in explaining how the creative process has been analyzed by researchers, academics and practitioners. These creativity models can be criticized for being no more than frameworks for enabling thought and reason to be developed. Fritz [44] was dismissive of several writers who have developed models of creativity, in terms of their understanding of the subject itself, "many of these people have never created anything other than theories about creativity" (p. 4). Jung [45] identified two creative processes at work, the rational and the subconscious. The former is a conscious process 
involving the systematic processing and adapting of existing knowledge, the latter is a process internalized within the individual's subconscious. Most models of the creative process seek to balance both these strands whereas a small number focus on one of the strands such as Barron [46] through his "psychic creation" model, this identifies creativity as being a mysterious process based upon the psychological and subconscious through four steps. Weisberg [47] identified from his work looking at the lives of great creators that moments of inspiration had been backed up by years of conscious work and preparation. The generation of an idea backed up by conscious preparatory analytical work also requires implementation to become fully realized. Contemporary researchers, academics and writers have developed models that embrace the complex aspects of the creative processes as it encompasses different developmental, contextual and applicability factors. In balancing creative and analytical thinking, models of the creative process have developed during the $20^{\text {th }}$ century focusing on the harnessing of creativity to enable problem solving solutions to be developed. The development and implementation of creative solutions requiring the input of individuals, the right environment to be in place as well as the combination of elements highlighted through models of the creative process.

The creative process was presented by Wallas [48] in a five stage model in 1926 which was not only one of the first to be developed but has also been used as a basis for the development of subsequent models [49]. Wallas [48] believed that creativity was a legacy of the evolutionary process which allowed humans to adapt to rapidly changing environments and through his five-stage model he sought to explain insights and illuminations within the creative process.

The model presented in (Table 2) is treated in some academic texts as only having four stages with the "intimation" phase shown as a sub stage. The first stage preparation, is where conscious preparatory work on an identified problem or issue takes place including understanding it fully as well as attempts at resolution. During the incubation stage the issue or problem becomes internalized by the individual into their subconscious to be processed prior to the development of their insight, illumination or creative idea. A period taken during the "incubation" stage may help the individual to be more creative and aid their problem-solving

Table 2. Breakdown of the wallas five stage model.

\begin{tabular}{cl}
\hline Stage & \multicolumn{1}{c}{ Description } \\
\hline Preparation & The problem is defined, observed and its dimensions studied \\
The problem is put to one side and \\
internalized into the unconscious mind \\
intimation & The creative person gets a "feeling" that a solution is on its way \\
illumination/insight & $\begin{array}{l}\text { The creative idea bursts emerge from its preconscious } \\
\text { processing into conscious awareness } \\
\text { verification }\end{array}$ \\
The idea is consciously verified, elaborated, and implemented
\end{tabular}

Sources: Adapted from [50]. 
abilities as well as enabling misleading approaches to be forgotten. Leading on from this, it can be argued that, if a period is not taken during the "incubation" stage the individual may become fixated on taking forward an inappropriate approach to solve a problem. At the illumination stage the problem or issue returns to the conscious and the individual has a new insight or idea regarding it. At the last stage in the model the idea or insight goes through a verification process to assess its appropriateness and its further development.

Torrance [51] sees the work of Wallasas forming a lot of the teaching on creative thinking and that it has influenced the development of other models of the creative process. Wallas [48] noted that during the creative process outlined in his model the individual can return to earlier stages. The first and last stages of his model are placing purposeful preparation and critical verification together suggesting that critical and analytical thinking complement each other rather than contrasting against each other. It can be said that those who think creatively study, analyze, verify and judge but they have trained themselves to perceive, notice things, expect change and avoid making premature judgements. The implied theory behind Wallas' model is that creative thinking is a subconscious process, it cannot be directed and that both creative and analytical thinking are complementary.

Building on the work of Wallas, Rossman [52] looked at the creative processes employed by 710 inventors and used the results obtained through a survey to develop a seven stage model [43]. This model begins with stages to observe and analyze a "need or difficulty" which may be reflective of his survey respondents but not necessarily a requirement of the creative process. The implication is that a "need or difficulty" has to exist and be identified before the creative process can take place. Rossman [52] has also added a final stage to "experiment and test the best fitting solution", which may also be reflective of the survey respondents. This model has connotations of a positivist empirically based approach to augmenting creativity through a controlled process as opposed to a process that is built around enhancing a creative spark that has ignited. An element of mystery is still attached to the creation of an idea in Rossman's model although the process identifies ideas as emerging at stage six as a response to an assessed need.

Table 3 shows Rossman's seven stage model which begins with stages that observe and identify a need prior to generating a creative idea, in contrast, Wallas [48] whose model begins with preparation and incubation stages which develops an environment to foster creativity. The development of a creative idea is shown in Wallas's model as an illumination which is inspirational which differs from Rossman's model where the creative idea is seen as emerging through an analytical process. Unlike Wallas, Rossman [52] does not consider the processing of new ideas or insights that appear at the illumination stage to be subject to the subconscious "the assumption that the subconscious is responsible for the final solution is, however, no answer to the problem. It merely amounts to giving a name to a thing which mystifies and puzzles us" [52]. 
Table 3. Breakdown of rossmans seven stage model.

\begin{tabular}{cl}
\hline Stage & \\
\hline One & Observation of a need/difficulty \\
Two & Analysis of the need \\
Three & A survey of all available information \\
Four & A formulation of all objective solutions \\
Five & A critical analysis of these solutions to assess their advantages/disadvantages \\
Six & Emergence of the new idea \\
seven & Experimentation to test out the best fitting solution
\end{tabular}

Source: Adapted from [43].

The balance between the imaginative/uncontrolled aspects of creativity and the processes to analyze as well as control them are shown in the development of different models that try and explain the creative process. This could be said to be a microcosm of the historical view that creativity is linked to flair. Imagination, genius, artistic venture and it is uncontrollable together with a more contemporary view that has sought to harness, engage, understand, control and to use the energies of creative thought in a positive way. Taking elements of Wallas's work forward, Osborn [53] developed a seven-stage model (Table 4) for creative thinking that balances both analysis and imagination.

As in the Wallas model, Osborn [53] includes the incubation stage, but his model shares a number of similarities with Rossman's seven stage model. These include an assessment of a need, the gathering of data relating to this need, the assembly and selection of a solution as well as experimentation relating to the selected solution. Like Wallas [48], Osborn [53] links creativity to the subconscious whereas Rossman [52] links it to a more rational and analytical approach. Wallas saw the creative process as an ongoing one whereby a "single achievement or thought" as "the making of a new generalization or invention" which can be dissected into a "continuous process, with a beginning, and a middle and an end" [48]. The stages within these models of the creative process can be seen as not being stages at all but processes occurring during creation which blend together. To be successful the creative process is described as "flow" by Csikzentmihalyi [54] whereby it is the result of the coming together of elements within a system; culture, an individual bringing novelty forward and external people who verify the idea or insight. He sees the role of the creative individual as being a link in the chain of a longer creative process and he sees creativity as "the cultural equivalent of the process of genetic changes that result in biological evolution, where random variations take place in the chemistry of our chromosomes, below the threshold of consciousness" [54].

Osborn postulated that creative ideas are trapped in the minds of individuals because of the fear that people have of rejection if they are put forward. Osborn [53] [55] [56] [57] developed brainstorming as a technique to be used to improve 
Table 4. Breakdown of the Osborn seven-step model.

\begin{tabular}{cc}
\hline Stage & Description \\
\hline Orientation & Pointing up the problem \\
Preparation & gathering pertinent data \\
Analysis & breaking down the relevant material \\
Ideation & piling up alternatives by way of ideas \\
Incubation & letting up, to invite illumination \\
Synthesis & putting the pieces together \\
Evaluation & judging the resulting ideas
\end{tabular}

Source: Adapted from [43].

the generation of ideas, especially in group meeting through harnessing the groups collective knowledge and interaction to develop ideas. This process encourages participants to contribute to idea generation through an open thinking approach with equal weight put on each submission. Osborn identified four basic rules to be applied when using the brainstorming process; criticism is ruled out, freewheeling is welcomed, quantity is wanted, and combination/improvement are sought [53]. Rossiter and Lillien [58] see the generation of "creative ideas" as "vital to business success" and highlight that the principles behind brainstorming have "evolved considerably" since Osborn put forward the process. From the body of literature that has developed since the early 1950's, Rossiter and Lillien identify six principles that have emerged that should be used with the brainstorming process; there should be instructions for each planned session, a target should be set for the number of ideas to be generated, ideas should initiated by individuals, initiated ideas should be refined group interaction, individuals should select the final idea through a voting process and session times should be controlled to short periods (15 minutes for initial idea generation and 2 hours for refining/selection) [58].

The combination of imagination and control has been a continuing aspect of the development of models of creativity seeking to systemize techniques to enable the directing and analysis of creativity. An example of this is the Parnes-Osborn Creative Problem Solving (CPS) model which has developed alongside the use of brainstorming technique since the 1960's [43]. Osborn introduced CPS with 3 steps-fact finding, idea finding and solution finding and this was refined by Parnes [59] into a five step model and again by Isaksen \& Treffinger [43] who added a sixth step. In the model the first two steps (objective and fact finding) and last two steps (solution and acceptance finding) require the use of analytical thinking and the middle two steps (problem and idea finding) require the use of creative thinking.

Table 5 shows the Parnes-Osborn CPS model which builds on the Osborn seven stage model and Rossman's stage model through a rational, analytical approach to harnessing creativity to solve an identified problem or achieve a goal 
Table 5. Breakdown of the Parnes-Osborn CPS model.

\begin{tabular}{cc}
\hline Stage & Description \\
\hline One & Objective finding-identifying the goal \\
Two & Fact finding-gather data about the goal \\
Three & Problem finding-identifying potential problems \\
Four & Idea finding-generating potential solutions \\
Five & Solution finding-developing the solution \\
Six & Acceptance finding-implementing the solution \\
\hline
\end{tabular}

Source: Adapted from [43].

[43]. The CPS model treats creativity as a tool that can be focused and used to generate solutions through an open, conscious and systemized approach whereas Wallas's model looks at creativity as a process that illuminates ideas for potential solutions through the subconscious of an individual, which can be a random and closed process. When comparing the CPS model to Rossman's model they both favor a rational and analytical approach to identifying the problem and implementation of the solution but differ in approach at the illumination stage where Rossman sees creativity as an unexplained process from which ideas emerge.

Koberg and Bagnall [60] put forward the "Universal Traveller Model" which has seven steps and again presents a balance between the imaginative and analytical aspects of creativity as well as a systematic approach to the development of the idea, generation of options, analysis and practical thinking. Step one of this model asks that that the user accepts the situation as it stands and to view this as a challenge unlike the other stage models where at step one the user is asked to; prepare for the problem or issue (Wallas), observe the problem or issue (Rossman), point to the problem or issue (Osborn) and find the problem or issue (Parnes-Osborn).

Koberg and Bagnall present their model (Table 6) as a map and the creative process as like taking a journey, starting with the problem and ending with a solution, using a process that they describe as "universally relevant" in that "any problem, dream or aspiration, no matter its size or degree of complexity, can benefit from the same logical and orderly "systematic" process employed to solve world level problems' [60]. They based their model on the study of Cybernetics, human control systems, employing the systematic approach used to develop a model that consciously controls creativity to design solutions to problems. They state that the creative "problem solving (design) process" is a "sequence of stages... on a journey to a destination" which once experienced and learnt is internalized by the individual [60]. The steps in their model "need not be linear" [60] which allows for the random nature of the creative process, this was also recognized by Wallas who stated, "it is unlikely that creative procedure can ever by strictly formulated" [53]. The seven steps in their model were also identified by Koberg and Bagnallas alternating between being divergent or convergent as well as having an evaluation step at the end of the process for review and planning. 
Table 6. Breakdown of the Koberg \& Bagnall "universal traveler" model.

\begin{tabular}{cc}
\hline Stage & Description \\
\hline One & Accept the situation (as a challenge) \\
Two & Analyze (to discover the "world of the problem") \\
Three & Define (the main issues and goals) \\
Four & Ideate (to generate options) \\
Five & Select (to choose among options) \\
Six & Implement (to give physical form to the idea) \\
Seven & Evaluate (to review and plan again)
\end{tabular}

Source: Adapted from [43].

This contrasts with the other stage models where the focus is on verification of the solution (Wallas), testing of the solution (Rossman), judging the solution (Osborn) and accepting/implementing the solution (Parnes-Osborn).

Models of creativity have also been developed to reflect certain contexts and specific environments such as engineering, commercial and business planning. These models still look to achieve a balance of creative and analytical thinking. An example of this is a model put forward for creative strategic planning by Bandrowski's process for creative strategic planning. In this model (Table 7), Bandrowski places "judgment" in the middle as an important part of the analytical part of the process and he specifies the specific creative skills that are to be used to achieve the result through the process including skills in insight development, creative leaps, and creative contingency planning [61].

Other models also look at providing a greater proportion to the external reality that an individual is applying their creativity to as well as the internal processes that they are employing, an example of this is the model put forward by Fritz as the "process for creation" [44]. He identifies the beginning of the process as the creative acts of conception and vision followed by analysis of current reality, action, evaluation, public scrutiny (building momentum), and completion as well as seeing the creative process is cyclical in nature-"living with your creation" being a meaningful end part of the process that leads to the next creative conception and vision.

Fritz's model, which is shown in Table 8 focuses on the creative aspects of the individual and was sceptical of formulaic approaches to the classification of the creative process presented by other models. The stages identified in the models of Wallas, Rossman and Osborn focused on the identification of the problem and the application of a creative solution in contrast to Fritz whose focus is on the individual and the identification of problems and creative problem solving through their actions. The actions of individuals are fundamental to the identification of a problem as well as its solution and the level of motivation that an individual has affects these actions. A range of factors can impact on motivation including autonomy, ownership, influence, reward, challenge as well as personal 
Table 7. Breakdown of the Brandowskis model for creative strategic planning.

\begin{tabular}{cc}
\hline Stage & Description \\
\hline Analysis & standard planning, insight development \\
Creativity & creative leaps, strategic connections \\
Judgment & concept building, critical judgment \\
Planning & action planning, creative contingency planning \\
Action & flexible implementation, monitoring results \\
\hline
\end{tabular}

Source: Adapted from [43].

Table 8. Breakdown of the fritz' process for creation.

\begin{tabular}{cc}
\hline Stage & Description \\
\hline One & Conception \\
Two & Vision VIV Vision \\
Three & Current reality \\
Four & Take action \\
Five & Adjust, learn, evaluate, adjust \\
Six & Building momentum \\
Seven & Completion \\
Eight & Living with your creation \\
\hline
\end{tabular}

Source: Adapted from [43].

behaviour characteristics. In the literature relating to the motivation of staff working in organizations' these factors can be identified; being in control, having independence, owning and influencing your own work [62] [63] [64]; requirements to perform, achieve targets and timescales [65] [66] [67].

\section{Innovation: Social Housing}

A significant amount of the literature identifies looks at innovation within social housing relating to the design and build of housing, reduced carbon usage and sustainable construction [68]-[76]. Innovation in technological advances in medicine and health care which is applied to housing services, mostly used by elderly people through telecare and assistive technologies [77]-[82]. There is very limited literature relating to innovation across the whole services provided by Housing Associations as social housing providers. Two studies that looked at innovation in HAs were undertaken by Walker \& Jeanas [83] and a further study undertaken by Walker et al. [84]. Both used a two-dimensional typology put forward by Osborn [85] to look at innovations within their research studies.

This model built on the traditional split of innovation between product and process allowing for "innovation to occur at any stage of the life cycle thereby highlighting discontinuity (innovation) and continuity (organizational development) along the dimensions of services and users" [84]. Within the two-dimensional 
model, the first dimension focuses on the impact of organizational change upon the services that are delivered, and these are identified as existing or new ones which also includes the discontinuity of services. The second dimension focuses on the relationship of an organizational change to its users both new and existing as well as how their needs are met "which involves end-user discontinuity" [84].

Four types of innovation were identified: the first is total innovation which includes "discontinuous change that is new to the organization and serves a new user group", the second is expansionary innovation whereby "the change involves offering an existing service of the organization to a new user group", the third is evolutionary innovation whereby "the change involves providing a new service to the existing user group of an organization" and the final classification is developmental innovation where "the services of an organization to its existing user group are modified or improved" [84].

The information within Table 9 is plotted on an XY graph format whereby the two-dimensional typology and innovations identified are plotted against the four categories in Figure 1.

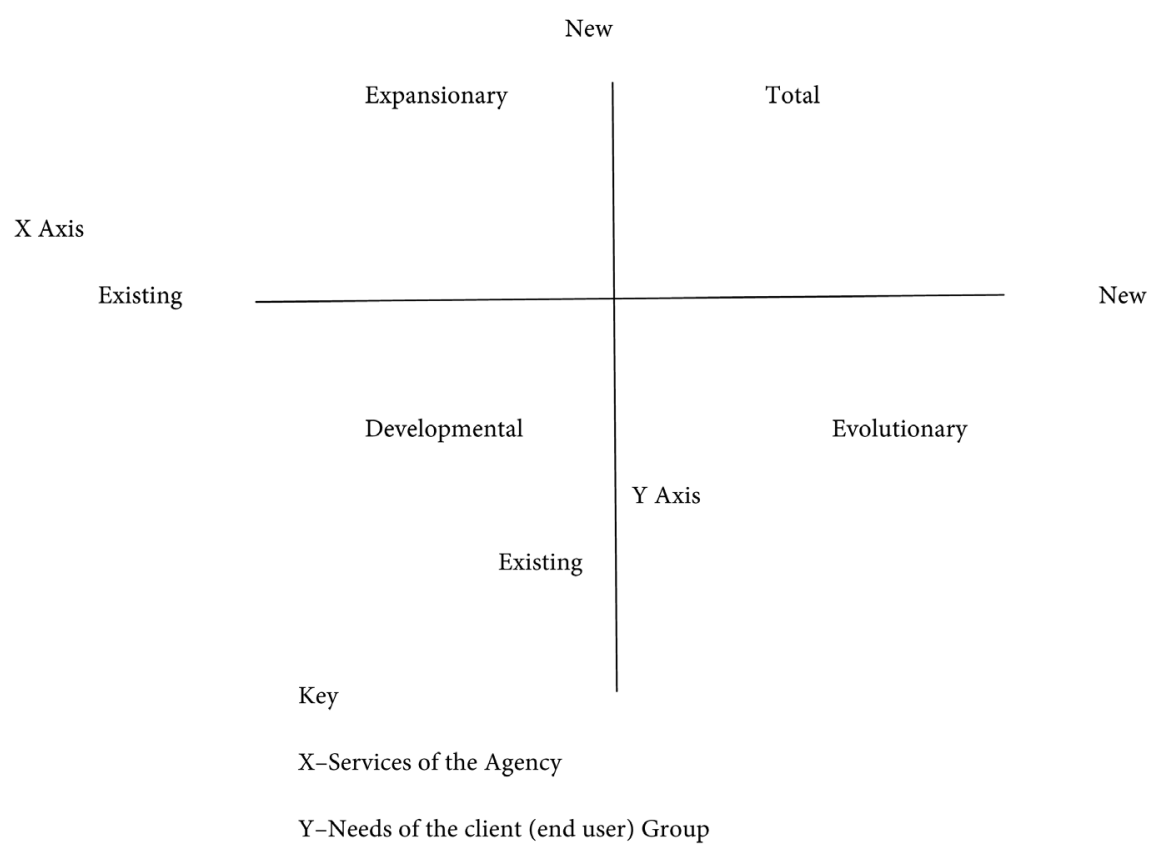

Figure 1. Typology of social policy innovation. Source: [85].

Table 9. Typology of public services innovation.

\begin{tabular}{ccc}
\hline & \multicolumn{2}{c}{ Users } \\
\cline { 2 - 3 } Services & New & Existing \\
\hline New & Total Innovation & Evolutionary \\
Existing & Expansionary & Developmental \\
\hline
\end{tabular}

Source: Adapted from [85]. 
In the first study, Walker and Jeanas [83] researched innovation in three housing associations in the late 1990s. The organizations' selected for the case studies represented the larger HAs in England who provided the most rented accommodation. A main problem identified with the case study approach was that it was not possible to gain a representative sample of housing providers as the sector is so diverse with no two organizations' being the same [83]. The identified innovations were focused under six areas of activity: cultural change; customer focus/information technology; diversification; new management techniques; organizational expansion and organizational structure. Many of these were internally focused emphasizing service changes and reflecting the financial, commercial, customer service and performance within an operating environment that was constantly changing and becoming increasingly competitive.

From the study (Table 10), the researchers found that in relation to new innovations change is discontinuous and radical, though more limited, incremental innovation takes place through change. It was found that the iterative and dynamic nature of innovation make the process of classifying them problematic not only because this process can be subjective but also because the innovations themselves change through time. A further study [84] carried out on innovation in housing associations also measured innovations that had been identified against Osborn's two-dimensional typology. Both studies highlighted several common themes that emerged from the transformation of the sector during the 1990s including: diversification of activity into regeneration, community facilities, care, special needs, private renting and contract management; the adoption of new organizational forms through mergers and group structures; a greater emphasis on a business ethos and management; and, a changing regulatory regime [86] [87] [88].

\section{Conclusion}

This study shows that there is a process connected with innovation and that there are different definitions within the academic literature about innovation. Innovation can be considered as being product or process that is new or is existing

Table 10. Classification of case study HA innovations.

\begin{tabular}{|c|c|c|}
\hline \multirow{2}{*}{$\begin{array}{c}\text { Organization } \\
\text { Innovation } \\
\text { Classification }\end{array}$} & \multicolumn{2}{|c|}{ Innovation Areas } \\
\hline & Area & Example \\
\hline Total & Diversification & Private Renting \\
\hline \multirow{3}{*}{ Evolutionary } & Customer Focus & Call Centres \\
\hline & Diversification & Housing Plus \\
\hline & Organizational Structures & Network Form, Demonstration Project \\
\hline Expansionary & Organization Expansion & $\begin{array}{l}\text { Stock Transfers, Mergers, Contract } \\
\text { Management, Geographical Growth }\end{array}$ \\
\hline Developmental & New Management Techniques & Business Focus, Performance Targets \\
\hline
\end{tabular}

Source: Adapted from [83]. 
but has been improved. There are different models regarding the process of innovation and from these it can be identified that there is a strong link to creativity as part of the innovation process. In looking at the application of innovation in social housing as part of the public sector this study has focused on two academic studies which looked at Housing Associations and Innovation and these identified that innovations can be seen with a typology as new products or services or improvements on existing products and services. Further research could be undertaken to look at innovation within the social housing sector within the United Kingdom within the twenty first century.

\section{Acknowledgements}

The author acknowledges help from his $\mathrm{PhD}$ supervisors at the University of Cumbria in researching the area of innovation.

\section{References}

[1] Godin, B. (2008) Innovation: The History of a Category. Montreal: Project of the Intellectual History of Innovation, Working Paper No. 1, p. 26.

[2] Skinner, M. and Hanlon, N. (2015) Ageing Resource Communities: New Frontiers of Rural Population Change, Community Development and Voluntarism. Routledge, New York, London.

[3] Bannet, E. (2007) Quixotes, Imitations and Transatlantic Genres. Eighteenth Century Studies, 40, 553-569.

[4] Force, P. (2005) Innovation as Spiritual Exercise: Montaigne and Pascal. Journal of the History of Ideas, 66, 17-35. https://doi.org/10.1353/jhi.2005.0026

[5] Cole, B. (1995) Titan and the Idea of Originality in the Renaissance. In: Ladis, A., Wood, C. and Eiland, W.U., Eds., Craft of Art, University of Georgia Press, Athens, 86-112.

[6] Macleod, C. (1988) Inventing the Industrial Revolution: The England Patent System 1660-1800. Cambridge University Press, Cambridge.

https://doi.org/10.1017/CBO9780511522673

[7] Popplow, M. (1998) Protection and Promotion: Privileges for Inventions and Books for Machines in the Early Modern Period. History of Technology, 20, 103-124.

[8] Berg, M. (1999) New Commodities, Luxuries and their Consumers in EighteenthCentury England. In: Berg, M. and Clifford, H., Eds., Consumers and Luxury: Consumer Culture in Europe 1650-1850, Manchester University Press, Manchester, 63-85.

[9] Berg, M. (2002) From Imitation to Invention: Creating Commodities in EighteenthCentury Britain. Economic History Review, 55, 1-30.

https://doi.org/10.1111/1468-0289.00212

[10] Clifford, H. (1999) Concepts of Invention, Identity and Imitation in the London and Provincial Metal-Working Trades, 1750-1800. Journal of Design History, 12, 241-255. https://doi.org/10.1093/jdh/12.3.241

[11] Dumont, L. (1977) From Mandeville to Marx. University of Chicago Press, Chicago.

[12] Branigan, A. (1981) The Social Basis of Scientific Discoveries. Cambridge University Press, New York. 
[13] Sweezy, P.M. (1968) Karl Marx and the Industrial Revolution. In: Eagly, R.V., Ed., Events, Ideology and Economic Theory, Wayne State University Press, Detroit, 107-126.

[14] Rosenberg, N. (1976) Marx as a Student of Technology. Monthly Review, 28, 56-77. https://doi.org/10.14452/MR-028-03-1976-07_5

[15] Stern, B.J. (1927) Social Factors in Medical Progress. Columbia University Press, New York.

[16] Schon, D.A. (1967) Technology and Change: The Impact of Invention and Innovation on American Social and Economic Development. Delta Book, New York.

[17] Schumpeter, J.A. (1928) The Instability of Capitalism. The Economic Journal, 38, 361-386. https://doi.org/10.2307/2224315

[18] Schumpeter, J.A. (1934) The Theory of Economic Development: An Enquiry into Profits, Capital, Credit, Interest and the Business Cycle. Oxford University Press, London.

[19] Schumpeter, J.A. (1939) Business Cycles: A Theoretical, Historical, and Statistical Analysis of the Capitalist Process. McGraw-Hill, New York.

[20] Schumpeter, J.A. (1942) The Process of Creative Destruction. In: Capitalism, Socialism and Democracy, Chapter 7, Harper, New York.

[21] Schumpeter, J.A. (1947) The Creative Response in Economic History. Journal of Economic History, 7, 149-159. https://doi.org/10.1017/S0022050700054279

[22] Fagerberg, J., Mowery, D.C. and Nelson, R.R., Eds. (2005) The Oxford Handbook of Innovation. Oxford University Press, Oxford.

[23] Malerba, F. and Brusoni, S., Eds. (2007) Perspectives on Innovation. Cambridge University Press, Cambridge. https://doi.org/10.1017/CBO9780511618390

[24] Linton, J.D. (2009) De-Babelizing the Language of Innovation. Technovation, 29, 729-737. https://doi.org/10.1016/j.technovation.2009.04.006

[25] OECD/Eurostat (2005) The Oslo Manual. OECD, Paris.

[26] Wolfe, R. (1994) Organizational Innovation: Review, Critique and Suggested Research Directions. Journal of Management Studies, 31, 405-431.

[27] Mulgary, G. and Albury, D. (2003) Innovation in the Public Sector. Strategy Unit, Cabinet Office, London.

[28] National Audit Office (NAO) (2009) Innovation across Central Government. The stationery Office, London.

[29] Australian National Audit Office (ANAO) (2009) Innovation in the Public Sector. Commonwealth of Australia, Canberra.

[30] Confederation of British Industry (CBI)/QUINETIQ (2008) Excellence in Service Innovation. CBI.

[31] Economic and Social Research Council (ESRC) (2008) Innovation Research Initiative Distributed Projects Cost Specification. ESRC, Swindon.

[32] Damanpour, F. and Schneider, M. (2009) Characteristics of Innovation and Innovation Adoption in Public Organisations: Assessing the Role of Managers. Journal of Public Resources and Theory, 19, 495-522. https://doi.org/10.1093/jopart/mun021

[33] De Vires, H.A., Bekkers, V.J.J.M. and Tummers, L.G. (2014) Innovations in the Public Sector: A Systematic Review. Ottawa IRSPM Conference, 9-11 April 2014.

[34] Evers, A., Ewert, B. and Brandsen, T., Eds. (2014) Social Innovations for Social Cohesion: 77 Cases from 20 European Cities 2010-14. European Commission, Nijmegen. 
[35] NESTA (2012) Plan 1: The Case for Innovation Led Growth. NESTA, London, 17.

[36] Seaden, G. and Manseau, A. (2001) Public Policy and Construction Innovation. Building Research \& Information, 29, 182-196. https://doi.org/10.1080/09613210010027701

[37] Cropley, D.H., Kaufman, J.C. and Cropley, A.J. (2011) Measuring Creativity for Innovation Management. Journal of Technology Management \& Innovation, 6.

[38] Klein, J.L. and Tremblay, D.G. (2011) Cultural Creation and Social Innovation as the Basis for Building a Cohesive City. Montreal, Canada.

[39] Florida, R. (2005) Cities and Creative Class. Psychology Press, New York.

[40] Markusen, A. (2006) Urban Development and the Politics of a Creative Class: Evidence from a Study of Artists. Environment and Planning A, 38, 1921-1940. https://doi.org/10.1068/a38179

[41] Vinacke, W. (1953) The Psychology of Thinking. McGraw Hill, New York.

[42] Wertheimer, M. (1945) Production Thinking. Harper, New York.

[43] Plsek, P. (1996) Working Paper: Models for the Creative Process. Directed Creativity.

[44] Fritz, R. (1991) Creating. Fawcett, New York.

[45] Jung, C.G. (1928) Contributions to Analytical Psychology. Kegan, Trench \& Trubner, London.

[46] Barron, F. (1988) Putting Creativity to Work. In: Sternberg, R., Ed., The Nature of Creativity, Cambridge University Press, Cambridge.

[47] Weiberg, R.W. (1993) Creativity: Beyond the Myth of Genius. Freeman \& Co., New York.

[48] Wallas, G. (1926) Art of Thought. Brace and Company, New York, 79.

[49] Simonton, D.K. (1999) Origins of Genius: Darwinian Perspectives on Creativity. Oxford University Press, Oxford.

[50] Truman, S. (2011) A Generative Framework for Creative Learning: A Tool for Planning Creative-Collaborative Tasks in the Classroom. Transnational Working Papers, No. 1101. Border Crossing.

[51] Torrance, E.P. (1988) The Nature of Creativity as Manifest in Its Testing. In: Sternberg, R.J., Ed., The Nature of Creativity, Cambridge University Press, Cambridge, England.

[52] Rossman, J. (1931) The Psychology of the Inventor. Inventors Publishing, Washington DC.

[53] Osborn, A. (1953) Applied Imagination. Charles Scribner, New York, 114.

[54] Csikszentmihalyi, M. (1997) Finding Flow: The Psychology of Engagement with Everyday Life. Basic Books, New York, 7.

[55] Osborn, A. (1952) Your Creative Power: How to Use Imagination. Charles Scribner, New York.

[56] Osborn, A. (1963) Applied Imagination: Principles and Procedures of Creative Problem Solving. 3rd Edition, Charles Scribner, New York.

[57] Osborn, A. (1948) Your Creative Power. Charles Scribner, New York.

[58] Rossiter, J.R. and Lillien, G.L. (1994) New "Brainstorming” Principles. Australian Journal of Management, 19, 61-72. https://doi.org/10.1177/031289629401900104

[59] Parnes, S.J. (1967) Creative Behaviour Guidebook. Scribner, New York.

[60] Koberg, D. and Bagnall, J. (1974) The Universal Traveller. W Kaufman, Los Altos, CA, p. 7, 16, 27. 
[61] Bandrowski, J.F. (1985) Creative Planning Throughout the Organization. American Management Association, New York.

[62] Bailyn, L. (1985) Autonomy in the Industrial R \& D Lab. Human Resource Management, 24, 129-146. https://doi.org/10.1002/hrm.3930240204

[63] Paolillo, J.G. and Brown, W.B. (1978) How Organisation Factors Affect R \& D Innovation. Research Management, 21, 12-15. https://doi.org/10.1080/00345334.1978.11756463

[64] Pelz, D.C. and Andrews, F.M. (1966) Scientists in Organisations: Productive Climates for Research and Development. Wiley, New York.

[65] Amabile, T.M. and Gitomer, J. (1984) Children's Artistic Creativity: Effects of Choice in Task Materials. Personality \& Social Psychology Bulletin, 10, 209-215. https://doi.org/10.1177/0146167284102006

[66] Amabile, T.M. and Gryskiewicz, N. (1989) The Creative Environment Scales: The Work Environment Inventory. Creative Research Journal, 2, 321-254. https://doi.org/10.1080/10400418909534321

[67] Amabile, T.M. (1994) The Delicate Balance of Managing for Creativity. $R \& D$ Innovator, 3, 1-9.

[68] Kaluarachi, Y. (2015) 8. Challenges to Leaders in Promoting Innovative and Sustainable Social housing In the UK. In: Opoku, A. and Ahmed, V., Eds., Leadership and Sustainability in the Built Environment, Taylor and Francis Group, Abingdon, 109-122.

[69] Marchesi, M., Kim, S.G. and Matt, D.T. (2015) Assessing the Design Innovation Potential of Timber Prefabricated Housing through Axiomatic Design. ASME 2015 International Mechanical Engineering Congress and Exposition, Houston, TX, 13-19 November 2015, 10 p. https://doi.org/10.1115/IMECE2015-50517

[70] Hjort, B. and Widén, K. (2015) Introduction of Sustainable Low-Cost Housing in Ethiopia-An Innovation Diffusion Perspective. Procedia Economics and Finance, 21, 454-460. https://doi.org/10.1016/S2212-5671(15)00199-9

[71] Nanyam, V.N., Basu, R., Sawhney, A. and Prasad, J.K. (2015) Selection Framework for Evaluating Housing Technologies. Procedia Engineering, 123, 333-341. https://doi.org/10.1016/j.proeng.2015.10.044

[72] Forster, A.M., Fernie, S., Carter, K., Walker, P. and Thomson, D. (2015) Innovation in Low Carbon Construction Technologies: An Historic Analysis for Obviating Defects. Structural Survey, 33, 52-72. https://doi.org/10.1108/SS-03-2014-0013

[73] Madeddu, M., Gallent, N. and Mace, A. (2015) Space in New Homes: Delivering Functionality and Liveability through Regulation or Design Innovation? Town Planning Review, 86, 73-95. https://doi.org/10.3828/tpr.2015.5

[74] Abbott, C., Sexton, M. and Barlow, C. (2015) Regulation and Innovation in New Build Housing. In: Orstavik, F., Dainty, A. and Abbott, C., Eds., Construction Innovation, John Wiley \& Sons, Ltd., Chichester, 79-88.

[75] Pässilä, P., Pulkka, L. and Junnila, S. (2015) How to Succeed in Low-Energy Housing-Path Creation Analysis of Low-Energy Innovation Projects. Sustainability, 7, 8801-8822. https://doi.org/10.3390/su7078801

[76] Springer, D. and German, A. (2015) New Whole-House Solutions Case Study: Zero Energy Ready Home Multifamily Project: Mutual Housing at Spring Lake (No. DOE/GO-102015-4690). ARBI.

[77] Wigfield, A., Moore, S., Buse, C. and Fry, G. (2012) Workforce Development for Assisted Living Technology: Understanding Roles, Delivery and Workforce Needs. 
Centre for International Research on Care, Labour and Equalities University of Leeds (CIRCLE), Found, 35.

[78] Marriot, P., Hinshaw, K., Nayar, R. and Emmerson, C. (2013) Development of a Multi Matrix Multi Partner Telehealth Model in Pregnancy Care in South of Tyne and Wear, UK. International Journal of Integrated Care, 13, 1-2. https://doi.org/10.5334/ijic.1408

[79] Parker, S.G. (2013) Telecare for an Ageing Population? Age and Ageing, 42, 424-425. https://doi.org/10.1093/ageing/aft056

[80] Hunter, R.H., Sykes, K., Lowman, S.G., Duncan, R., Satariano, W.A. and Belza, B. (2011) Environmental and Policy Change to Support Healthy Aging. Journal of Aging \& Social Policy, 23, 354-371. https://doi.org/10.1080/08959420.2011.605642

[81] Williamson, T. (2011) Grouchy Old Men? Promoting Older Men's Mental Health and Emotional Well Being. Working with Older People, 15, 164-176. https://doi.org/10.1108/13663661111191284

[82] Wilder, A.R. (2011) A Review of: “Aging Friendly Technology for Health and Independence: 8th International Conference on Smart Homes and Health Telematics, Icost 2010". Journal of Technology in Human Services, 29, 142-146. https://doi.org/10.1080/15228835.2011.588052

[83] Walker, R. and Jeanas, E. (1999) Innovation in a Regulated Service: The Case of English Housing Associations. Paper Given at ENHR "The Process of Change in Housing" Conference, Laboratrio Nacional de Engenharia Civil, Lisboa, Portugal, 27-28 May 1999.

[84] Walker, R., Jeanas, E. and Rowlands, R. (2002) Measuring Innovation-Applying the Literature-Based Innovation Output Indicator to Public Services. Public Administration, 80, 201-214. https://doi.org/10.1111/1467-9299.00300

[85] Osborn, S.P. (1998) Voluntary Organisations and Innovation in Public Services. Routledge, London.

[86] Clapham, D. and Evans, A. (1998) From Exclusion to Inclusion: Helping to Creating Successful Tenancies and Communities. Hastoe Housing Association, London.

[87] Mullins, D. and Riseborough, M. (1999) Changing with the Times. University of Birmingham, Birmingham.

[88] Walker, R. (2000) The Changing Management of Social Housing: The Impact of Externalisation and Managerialism. Housing Studies, 15, 281-299.

https://doi.org/10.1080/02673030082397 